\title{
GEOGRAFIAS DA REGULAÇÃO E GOVERNANÇA: perspectivas para a análise regional e urbana
}

\section{GEOGRAPHIES OF REGULATION AND GOVERNANCE:} applications for regional and urban analysis

\author{
Marcos Barcellos de Souza \\ Doutor em Desenvolvimento Econômico pela UNICAMP \\ barcellos.marcos@hotmail.com
}

\begin{abstract}
RESUMO
O presente trabalho pretende apontar alguns elementos críticos presentes na iteratura anglo-saxã sobre geografias da regulação e da governança e discutir sua validade para a compreensão de padrões de urbanização. Para tal, busca-seentender as formas de imersão sócio-espacial das localidades e suas relações com regimes regulatórios, mecanismos de governança e transformações do Estado. Propomos uma construção analítica que destaque os aspectos institucionais, territoriais e não territoriais dagovernança urbana e as formas extra-econômicas que orientam as diversas estratégias de competitividade das cidades atuais.Discutimos o aspecto multiescalar dos mecanismos de governança e a complexidade envolvida na sua regulação global.
\end{abstract}

Palavras-chave: Abordagem da Regulação; Governança; Imersão Sócio-Espacial; Escalas Espaciais; Urbanização.

\begin{abstract}
This paper highlights some critical elements in Anglo-Saxon literature on geographies of regulation and governance and discusses its validity for understanding patterns of urbanization. To this end, we intend to understand the socio-spatialembededdness of localities and their relationships to regulatory regimes, governance mechanisms and transformations of the state. We propose an analytical framework that highlights the institutional, territorial and non-territorial aspects of urban governance and the extraeconomic forms that guide the various strategies of competitiveness adopted by contemporary cities. We discuss the multiscalar aspects of governance mechanisms and the complexity involved in its global regulation.
\end{abstract}

Keywords: Regulation Approach; Governance; Socio spatial embededdness; Spatial Scales; Urbanization. 


\section{Introdução}

O reconhecimento, em meados dos anos 80, de que "as instituições importam" para a Geografia Econômica não significou que estas importam para todos os a(u)tores da mesma maneira. Este reconhecimento foi acompanhado, pouco depois, pela constatação de que a "geografia importa" para o estudo das instituições, um campo no qual a análise histórica sempre exerceu nítido predomínio. Em certa medida, o desenvolvimento teórico foi consequência dos esforços de geógrafos radicais dispostos a sustentar que não apenas o espaço é socialmente construído, mas que também a sociedade é espacialmente construída, e sua organização espacial afeta o modo como ela funciona (MASSEY, 1992). A preocupação com a importância das instituições para a reprodução social e um crescente interesse pelo espaço nas Ciências Humanas (idem) convergiram em formulações originais, como a correspondência entre imersão social e imersão espacial, a constatação de que um processo de path dependency é também de placedependencye a definição de espaço institucional e densidade institucional (MARTIN, 2000).

A "virada institucional" na Geografia compartilha uma preocupação com formas extraeconômicas, processos sócio-culturais, sistemas de regras, procedimentos e convenções (formais/informais) e com o caráter contextualmente específico e geograficamente desigual de arranjos institucionais. No entanto, as abordagens sobre instituições são amplamente diferenciadas, sendo impossível identificar "uma geografia econômica institucionalista plenamente articulada" (MARTIN, 2000, p. 78).

Jamie Peck (2000) assinaladuas "macro abordagens" como pontos de entrada para entender a virada institucional: os debates sobre flexibilização e globalização. No primeiro caso, o autor defende um maior rigor teórico com vistas a evitar a associação entre acumulação flexível e pós-fordismo, enquanto no debate sobre globalização Peck destaca a preocupação com as transformações da ordem regulatória, com ênfase na "reorganização qualitativa" do Estado. Neste sentido, o reescalonamento (alterações nas relações entre escalas espaciais) do Estado deve ser entendido como o reescalonamento de sua integridade institucional (MACLEOD, 2001). Ron Martin (2000) argumenta que uma abordagem institucionalista para a geografia econômica deve enfatizar como o espaço molda a interação entre ambiente institucional e arranjos institucionais no processo complexo de evolução da paisagem econômica.

Geo UERJ. Rio de Janeiro - Ano 16, nº. 25, v.2, $2^{\circ}$ semestre de 2014, pp.122-141

ISSN: 1415-7543 E-ISSN: 1981-9021

http://www.e-publicacoes.uerj.br/index.php/geouerj 
Para Gordon MacLeod e Mark Goodwin (1999), três linhas de trabalho recentes conferem às instituições um papel central nas abordagens sobre a reestruturação regional e urbana: i) a literatura sobre regimes urbanos, máquinas de crescimento e coalizões regionais-urbanas; ii) a discussão de "learning regions" e sua "densidade institucional"; e iii) a Abordagem da Regulação para o estudo da governança local.

Na literatura em geral é possível imaginar uma espécie de continuum multidimensional, onde a concepção de instituições varia desde o neo-marxismo regulacionista até um novo-institucionalismo baseado em contratos e próximo da economia neoclássica; desde uma concepção da economia como "processo instituído", de inspiração em Karl Polanyi, até uma abordagem mais instrumental e focada em organizações formais e regras; e de uma "economia política cultural" até uma visão mercantilizada da cultura, que enfatiza seu papel funcional para estimular (ou atrair) determinado tipo de criatividade e desencadear certos processos cognitivos.

Em meio a tantas divergências, defendemos um tratamento das instituições como elementos constitutivos da economia, e não necessariamente funcionais para seu desempenho. Gordon MacLeod (2001) destaca a preocupação crescente com as instituições e superestrutura, em resposta aos debates "produtivistas" anteriores que enfatizavam as vantagens das novas tecnologias de informação e do processo de trabalho pós-fordista. No entanto, o autor alerta para os riscos de se incorrer num "institucionalismo leve", que obscurece as assimetrias de poder entre os agentes e o papel do Estado em "moldar a fábrica regional e urbana", além de reificar a densidade institucional e o capital social local sem considerar que estes não explicam o desenvolvimento desigual.

O institucionalismo leve da ortodoxia regional-urbana é reforçado pelo caráter focalizado das políticas urbanas conservadoras e se combina com determinadas narrativas escalares e representações escalares do regionalismo dominante. Por este motivo, a necessidade de conectar a mudança regional e urbana com as estratégias de atores transnacionais e "a natureza dinâmica e configurações escalares do Estado" (MACLEOD, 2001, p.1153) é um dos maiores desafios para uma abordagem institucional da regionalização e urbanização. Neste contexto, identificar mudanças institucionais decorrentes da ação do Estado se torna uma tarefa importante, pois estas 
podem decorrer de pressões com origens geográficas específicas ou refletir o descontentamento do governo central com o desempenho de estruturas institucionais em certas regiões.

A abordagem institucionalista se torna útil também para entender a existência de determinada coerência na reprodução e regularização das relações capitalistas. Esta coerência não deve ser confundida com equilíbrio, tampouco com uma versão normativa de estabilidade. A necessidade de fixação e valorização do capital em determinados espaços é destacada, assim como o caráter temporário destes "ajustes" decorrente de contradições internas e externas e da natureza do desenvolvimento espacial desigual.

Conforme pretendemos demonstrar neste artigo, os arranjos institucionais interescalares cumprem papel crucial neste duplo processo: de um lado, por permitir a mobilização e circulação de certas estratégias, políticas e discursos e por "imergir" de formas distintas o mercado, apresentando vantangens diferenciadas para o capital; do outro, por serem o meio e objeto da reestruturação durante crises de legitimação social e crises da acumulação de capital.

A coesão destes ajustes regulatórios tem sido ainda questionada por trabalhos recentes que defendem uma perspectiva relacional e topológica. Entretanto, a tensão entre territorialidade e relacionalidade não pode ser solucionada pelo paradigma das redes, nem transcender a necessidade de alguma forma de imersão social, espacial e escalar destas relações, que não ocorrem num vácuo institucional. Ademais, esta tensão lança novos desafios sobre as formas de governança econômica e social que cumprem papel importante na regulação territorial.

O objetivo deste artigo é propor uma análise da produção de espaços regionais-urbanos a partir do seu entendimento como resultante de processos regulatórios, variegados e relacionais. Com base nestas características, pretendemos propor algumas bases para uma abordagem institucionalista da produção de complexos regionais-urbanos, que incorpore as quatro dimensões sócio-espaciais: escalas, territórios, lugares e redes (JESSOPetal, 2009) e possibilite o entendimento das formas de imersão sócio-espacial e regulatória das localidades. A organização do trabalho, além desta introdução, consiste 
numa revisão das tentativas de espacializar a Abordagem da Regulação, seguida da proposta de diálogo entre modos de regulação e modos de governança. O próximo passo é uma tentativa de aproximação da Abordagem da Regulação com uma interpretação neo-polanyiana sobre a questão da imersão social. Por fim, serão analisadas as condições para a construção do que chamamos de Sistemas Sociais de Produção de Complexos Regionais e Urbanos, inspirada na noção regulacionista/polanyiana de Sistemas Sociais de Produção.

\section{Revisitando os Modos Locais de Regulação}

A preocupação com a dinâmica institucional e contratos sociais estabelecidos na escala nacional tem sido, desde a década de 80 , objeto de crítica dos geógrafos anglo-saxões que se engajaram na Abordagem da Regulação. Esta agenda se expandiu devido aos esforços de uma "terceira geração" de regulacionistas a partir do início dos anos 90, que passou a incorporar preocupações com: i) o processo regulatório e sua constituição discursiva; ii) geografias de regulação e sua constituição escalar; iii) o Estado e a regulação política (MACLEOD, 1997).A preocupação em relacionar o caráter processual e contingente das práticas regulatórias com o desenvolvimento desigual em todas as escalas constituem aportes fundamentais para qualquer tentativa de espacializar a Abordagem da Regulação e tentar resolver o que Martin Jones (1997) definiu como o "enigma regulacionista": como entender as transformações locais num contexto de globalização e reestruturação produtiva?

Neste sentido, é importante ter em conta que qualquer ajuste regulatório está sujeito a alterações na ordem regulatória decorrentes do deslocamento sistêmico (surgimento de novas atividades para regular e mudança da natureza das atividades existentes) e dos limites espaciais da natureza regulatória, que levam a um processo de "arbitragem regulatória" (LEYSHON, 1992). A regulação, portanto, deve ser entendida como um processo, com ênfase em sua natureza contingente (MACLEOD, 1997) e nas estruturas institucionais e formas de produção emergentes.

Peck e Tickell (1992) argumentam que as regiões interagem com estruturas regulatórias regionais e nacionais de formas particulares. Esta interação (e sobreposição) de formas 
institucionais pode até mesmo ser disfuncional, como no caso de economias regionais que são prejudicadas pelas estratégias de acumulação nacionais. $\mathrm{O}$ desenvolvimento desigual seria resultado de uma interação diferenciada dos sistemas regionais deacumulação (a estrutura produtiva-tecnológica regional) com o modo nacional de regulação (que compreende as principais formas institucionais), produzindo déficits regulatórios.

A Abordagem da Regulação também foi utilizada no debate de regionalização, onde se associava a qualidade da regulação à coerência regional e sua maior preocupação era com os efeitos da fragmentação sobre a competitividade regional. Conforme alerta Brenner (1999), o problema com este tipo de análise reside no maior peso dado a aspectos industriais e setoriais em detrimento dos atributos urbanos e numa ênfase normativa exagerada na coerência regional em um contexto atual no qual é extremamente difícil entender as regiões como escalas geogáficas coerentemente definidas.

Chris Collinge (1999) evita priorizar analiticamente modos locais de regulação e oferece um tratamento estrutural de como a organização escalar da sociedade está relacionada à acumulação de capital e sua regulação, partindo da noção de divisão escalar ótima do trabalho e configuração de escalas dominantes e nodais para criar uma ordem social coesa, que depende da capacidade do bloco hegemônico regular e incorporar mudanças nas escalas dominantes.

A importância dos modos locais de regulação não foi ignorada pelos "regulacionistas parisienses" originais efoi acompanhada pelo maior interesse na questão da governança territorial. No entanto, o tratamento privilegiado das redes como modos de governança e a ênfase na proximidade territorial conferem demasiado destaque à sobreposição horizontal de formas institucionais e convenções na regulação local. Exagerada coesão é atribuída ao território, apesar do reconhecimento de que esta responde a processos de reestruturação da regulação global. Entretanto, os modos locais de regulação não devem ser confundidos com uma ênfase na meso regulação (contra LINS, 2006) ou na idéia equivocada de que as transferências regulatórias entre escalas são um jogo de soma zero (ver PECK E TICKELL, 1995). Pelo contrário, a qualidade da regulação local não está relacionada com o fato de ser rigidamenteterritorializada, mas sim na maneira como 
interage com a regulação supralocal, muitas vezes de formas sobrepostas - mesmo que possam ocorrer redundâncias.

Desta forma, a maior sensibilidade às dimensões sócio espaciais, acrescentada pela "terceira geração" de regulacionistas, pode enriquecer o entendimento dos processos regulatórios. Para tanto, torna-se necessário: i) reconhecer a importância das escalas e do lugar, além do território e das redes; ii) evitar a falsa dicotomia local/globali; iii) incorporar uma noção mais ampla para a regulação das relações sociais, que evite o viés centrado na firma; e iv) entender como as diversas entidades que atuam e são objeto da regulação estão conectadas por fluxos e estruturas territorializadas; em outras palavras, como são afetadas pela dialética mobilidade/fixidez e como uma noção exagerada de coerência (sobretudo regional) pode ser problemática.

Isso obviamente não significa afirmar que os processos regulatórios são aleatórios, mas que a coerência dos mesmos não pode ser "engessada" em termos de sua funcionalidade a um regime de acumulação. Neste sentido, conforme argumentam Jessop (1983) e Brenner (2004), a coerência das formas regulatórias deve ser entendida com base na unidade conferida pela estratégia de acumulação hegemônica e pelos projetos e estratégias espaciais do Estado ao produzir, mediar e administrar o desenvolvimento espacial desigual, o que representa desafios maiores de periodização.

Ademais, a relação entre governança e modos de regulação precisa ser expandida a ponto de incluir outros mecanismos de governança, que compreendam não apenas o mercado,hierarquias e redes, mas também o Estado, comunidades e associações (HOLLINGSWORTH E BOYER, 1997). As diferenças entre os arranjos institucionais hegemônicos em cada sistema são expressões do caráter variegado da urbanização.

\section{Governança e Variegação}


Durante a vigência do fordismo, podemos argumentar que as estratégias de acumulação nacionais impunham um tipo de corência forte, ou um encaixe estrutural mais simples sobre os sistemas espaciais regionais/locais. Após a crise fordista, a maior fragmentação e descentralização das decisões e do poder decorrentes da relativa desnacionalização do Estado, da de-estatização tendencial de regimes políticos, internacionalização dos regimes de política e a remercantilização das políticas econômicas e sociais (JESSOP, 2002a) implicam em novas geografias da regulação e da governança. Estas foram transformadas, por um lado, pela inclusão de novos atores, como organizações da sociedade civil, agências do Estado (ou semi-públicas) e novos níveis de governo; e de novas relações, como a emergência da governança local, parcerias público-privadas e redes interescalares de políticas. Por outro lado, a maior complexidade do capitalismo globalizado é caracterizada também por processos de reterritorialização e reescalonamento que determinam os objetos da regulação e governança(JESSOP, 1995). Em outras palavras, é preciso ter em conta que a globalização acarreta na busca de novas escalas territoriais do poder do Estado e do capital, e de novas formas não territoriais de governança (JESSOP, 2000b).

Neste contexto, a natureza do ajuste estrutural entre as formas econômicas e extraeconômicas é fundamental, por exemplo, para questões como a competitividade e inovação das economias nacionais e regionais e para as formas de internacionalização perseguidas por economias nacionais e empresas multinacionais (JESSOP, 2000b).

Além da complexidade, o reconhecimento das formas extra-econômicas (e novas interdependências destas com as formas econômicas) para a inovação e competitividade também é responsável pela busca de uma governança “de baixo para cima", não hierárquica e não mercantil que privilegia a negociação, comunicação e a transmissão de conhecimento entre os agentes através da imposição de uma coerência fraca. As tentativas recentes de impor uma coerência fraca através da coordenação estratégica interagem com outros esforços de promover um ajuste estrutural baseado na coerência forte. Neste sentido, as noções de bloco histórico, regime de acumulação, imersão societal e coordenação estratégica se encontram na necessidade de identificar os horizontes espaciais e temporais de dado ajuste espaço-temporal, nos quais uma 
coerência estruturada relativa é assegurada e alguns custos de assegurá-la são externalizados (JESSOP, 2000b).

A conformação de blocos históricos regionais ou locais assumirá maior "autonomia" e importância após a crise do fordismo, sobretudo em regimes federativos e descentralizados, onde há devoluções regulatórias e surgimento de novas oportunidades de parcerias (JESSOP, 1996).De um ponto de vista estratégico, as coalizões locais precisam estabelecer limites territoriais e temporais (utilizando práticas discursivas), assim como as escalas espaciais nas quais perseguirão seus objetivos. Para tanto, suas estratégias de acumulação devem considerar a posição na hierarquia urbana e na divisão internacional do trabalho, buscando a construção de uma complementaridade estruturada entre a economia local e ao menos um dos regimes de acumulação (regional, nacional e supranacional) que a envolvem (JESSOP, 1996, p. 64).

Durante o fordismo, ainda que houvesse certa variedade de estratégias perseguidas por coalizões locais/regionais, estas estavam subordinadas ao papel central das localidades na política social do Estado de Bem Estar (principalmente na Europa), na provisão de infra-estrutura local para apoiar a produção em massa e o consumo coletivo e, após os sintomas da crise, na concessão de subsídios competitivos para atrair novos empregos e evitar a perda de empregos existentes (JESSOP, 1996, p.67). Neste sentido, as localidades estavam conectadas às formas específicas de produção e administração do desenvolvimento desigual e acompanhavam as menores exigências de institucionalização e governança presentes na economia fordista, onde o Estado e o mercado eram os principais mecanismos de coordenação. Os requisitos para a urbanização na transição do Estado Nacional de Bem Estar Keynesianopara o Regime Pós-Nacional de Workfare Schumpeteriano $(S P W R)$ precisariam contemplar estratégias que favoreçam os seguintes elementos: o treinamento da mão de obra local, transferência de tecnologia, fortalecimento do capital de risco local, centros de inovação, incubadoras para pequenos negócios, parques científicos e tecnológicos, apoio ao empreendedorismo e à exportação, e inserção em redes transnacionalizadas de transferências de políticas locais (JESSOP, 1996, p.69-70). Algumas variantes destas estratégias estão sistematizadas no Quadro 1. 
Bob Jessop (2002a) argumenta que estas estratégias são interdependentes e complementares ao longo de determinada divisão escalar e espacial do trabalho. $\mathrm{O}$ neoliberalismo, em particular, tem notável capacidade de hibridização com as outras variantes do SWPR e necessita delas para se estabilizar e conter seus efeitos mais destrutivos.

Neste contexto, pode-se afirmar que não apenas atores econômicos são sujeitos da competição, mas também entidades políticas que representam espaços e lugares, como as cidades, regiões e nações. A justificativa para tal raciocínio baseia-se em três argumentos: i) a competição não se fundamenta apenas nas forças de mercado, então as condições extra-econômicas, que aumentam a competitividade das firmas, podem ter também significativa relevância para outros sujeitos; ii) uma localidade empreendedora, tal como as firmas, também necessita de características institucionais e organizacionais que sustentam um fluxo de inovação e que se localizam em um complexo espacializado, iii) as estratégias competitivas precisam ser explícitas e passíveis de serem atingidas. Jessop (1997) argumenta que a força das "cidades empreendedoras" depende da capacidade das narrativas que as sustentam em articular apropriadamente diagnósticos e soluções para a crise urbana com determinados discursos que as complementam e com formações institucionais e culturais mais amplas. Com efeito, nem todas as localidades serão bem sucedidas neste objetivo, mas é provável que tentarão alguma combinação de estratégias competitivas. 
Quadro 1 - Variantes do SWPR

\begin{tabular}{|c|c|c|}
\hline & Objetivos & Formas extra-econômicas \\
\hline Neocorporativismo & $\begin{array}{l}\text { Negociação da reestruturação por } \\
\text { atores privados, públicos e do } \\
\text { Terceiro Setor. Equilibrio entre } \\
\text { competição e cooperação }\end{array}$ & $\begin{array}{l}\text { Diversidades de associações, comunidades } \\
\text { políticas e networks voltadas para a } \\
\text { inovação. Parcerias Público Privadas } \\
\text { (PPPs). Concordância com políticas do } \\
\text { Estado é voluntária ou depende da auto- } \\
\text { organização de associações corporativas }\end{array}$ \\
\hline Neoestatismo & $\begin{array}{l}\text { Estado guia as forças do mercado em } \\
\text { apoio a uma estratégica econômica } \\
\text { nacional. Competição internacional } \\
\text { baseada na busca de vantagens } \\
\text { competitivas dinâmicas e neo- } \\
\text { mercantilismo }\end{array}$ & $\begin{array}{l}\text { Estado, através da: i) definição de alvos } \\
\text { estratégicos; ii) direcionamento das PPPs; } \\
\text { iii) treinamento e requalificação da mão de } \\
\text { obra }\end{array}$ \\
\hline Neocomunitária & $\begin{array}{l}\text { Aumentar a contribuição do Terceiro } \\
\text { Setor e da economia popular para o } \\
\text { desenvolvimento econômico. Foco em } \\
\text { espaços menos competitivos. Busca } \\
\text { de maior auto-suficiência }\end{array}$ & $\begin{array}{l}\text { Comunidades. Parcerias descentralizadas } \\
\text { entre o Estado, negócios e interesses } \\
\text { comunitários locais. Confiança. } \\
\text { Informalidade. }\end{array}$ \\
\hline Neoliberalismo & $\begin{array}{l}\text { Comodificação; mercantilização; } \\
\text { privatização; controle social. }\end{array}$ & $\begin{array}{l}\text { Desimersão social do mercado; } \\
\text { combinação das estratégias anteriores. } \\
\text { Políticas de work first no que tange ao } \\
\text { mercado de trabalho }\end{array}$ \\
\hline
\end{tabular}

Fonte: Elaboração própria com base em Jessop (2002a)

Há uma variedade de estratégias competitivas a serem perseguidas pelas localidades e estas dependerão da sua imersão sócio-espacial e sua consequente regulação social, que orientarão a coordenação econômica e as políticas urbanas. Neste sentido, as localidades, de forma semelhante às firmas, estão imersas em sistemas sociais sujeitos a constrangimentos decomunidades políticascom valores, crenças e tradições (HOLLINGSWORTH E BOYER, 1997), nos quais as formas extra-econômicas podem ser representadas pelos mecanismos de governança. Estes se aproximam dos princípios dos modos de integração de Polanyi (1944): reciprocidade (redes e comunidade); redistribuição (Estado e hierarquias) e troca (mercado).Conforme argumenta Peck 
(2013), os modos de integração podem ser encontrados em diversas combinações heterogêneas (e híbridas) e estabelecerão as bases para a organização das capacidades (re)produtivas e (re)distributivas em diversos espaços. A abordagem sugerida volta-se ao entendimento das economias regionais e urbanas reais, com seus padrões de institucionalização e contextos sócio institucionais. Essas economias reais são variegadas e ilustram como a expansão do mercado precisa ser contrabalanceada pela existência de formas extra-econômicas, configurando arranjos institucionais específicos.

No Quadro 2, apresentamos as principais relações associadas à governança das cidades empreendedoras.

\section{Quadro 2 - Governança e cidades empreendedoras}

\begin{tabular}{|l|l|}
\hline Comunidades & $\begin{array}{l}\text { "Sentido global de lugar" X Provincianismo; intensificação do espaço-tempo; novos } \\
\text { tipos de lugares de trabalho, consumo e moradia; economia popular; distritos industriais }\end{array}$ \\
\hline Associações & $\begin{array}{l}\text { Corporativismo local; associações de negócios; sindicatos; Consórcios Intermunicipais; } \\
\text { Quangos }\end{array}$ \\
\hline Redes & $\begin{array}{l}\text { Elites de negócios; regimes urbanos; transferência interjuridicionais e interescalares de } \\
\text { políticas; Parcerias Público-Privadas; cidades globais e cidades transfronteiriças }\end{array}$ \\
\hline Hierarquias & $\begin{array}{l}\text { Sistemas de planejamento; sistemas urbanos; coordenação federativa; grandes firmas em } \\
\text { rede e suas subcontratadas }\end{array}$ \\
\hline Estado & $\begin{array}{l}\text { Seletividade espacial do Estado; agências estatais, níveis de governo e instituições do } \\
\text { Estado; Regiões Metropolitanas; infra-estrutura; regulação; impostos }\end{array}$ \\
\hline Mercado & $\begin{array}{l}\text { Marketing urbano; mercantilização da cultura e criatividade como fatores de atração; } \\
\text { PMEs; }\end{array}$
\end{tabular}

Fonte: elaboração própria

A abordagem da governança, assim representada, enfatiza a "contingência das ordens", ou seja, a variedade de formas como determinadas "tarefas" - no caso, a adoção de estratégias competitivas e empreendedoras pelas cidades - podem empregar diferentemente os mecanismos de governança. Assim, além dos pesos diferentes, há possibilidade de diversas combinações híbridas entre estes mecanismos. Crouch et al (2001) reforçam a noção de que a coordenação global depende do aprofundamento da governança local e extra local, com ambas oferecendo oportunidades de ganhos. Mais 
do que isso, os modos de governança também se organizam de forma multiescalar, representando enormes desafios para a coordenação global.Dessa forma, o desempenho das localidades deve ser relacionado com regimes de acumulação supralocais, redes internacionais, a reestruturação e o reescalonamento do Estado e das firmas. As diferentes combinações entre os modos de governança favorecerão determinada variante espacial do Regime Pós Nacional de Workfare Regional.

A ênfase aqui proposta nas dimensões extra-econômicas da governança não exclui preocupações com os aspectos produtivos. Com efeito, acreditamos queos Sistemas Sociais de Produção de Complexos Regionais e Urbanos (SSPCRUs) são complementares aos "arranjos urbano-regionais" e às dinâmicas de polarização e complementaridades criadas entre localidades com diferentes estruturas produtivas (MOURA, 2010). A governança institucional das cidades empreendedoras extrapola seu território formal e as formas híbridas pelas quais o mercado se combina com as formas extra-econômicas nas suas estratégias contribuirão para a configuração de uma paisagem geo-institucional variegada dentro destes arranjos. Ademais, ajudam a ilustrar problemas da governança territorial regional relacionados a grandes projetos de investimento, cujos efeitos extrapolam a gestão municipal (CGEE, 2010).

Dito isto, é importante um cuidado especial com as condições nas quais a abstração da cidade como firma se torna um recurso analítico válido. $\mathrm{O}$ maior risco é incorrer em um "fetichismo espacial" no qual as localidades seriam tratadas como agentes econômicos próprios, com suas características determinadas. $\mathrm{Na}$ realidade, as localidades são entidades socialmente construídas que dependem de cenários econômicos, políticos, sociais e culturais particulares e realidades nas quais firmas, pessoas e outros agentes interagem (BATHELT E GLUKLER, 2003; p.121). Desta forma, é importante considerar como a política local é influenciada pela participação de atores poderosos, com graus de dependência local variáveis, em coalizões que visam melhorar suas posições em divisões espaciais e escalares do trabalho mais amplas. Assim, o fetichismo espacial é evitado quando a localidade deixa de ser definida em termos físicos, mas como uma estrutura social localizada e como um agente (COX E MAIR, 1991).

As significativas mudanças na hierarquia espacial fordista implicam que o ajuste espaço-temporal nacional não é mais suficiente para estabilizar a acumulação 
capitalista. A necessidade de criar novos ajustes espaço-temporais torna fundamental: i) o estabelecimento de novas escalas de atividade e a rearticulação e reescalonamento de poderes do Estado, formas institucionais e capacidades regulatórias; ii) administração de novas formas de des-territorialização e re-territorialização e iii) promoção de novas formas de desenvolvimento desigual através de políticas de competição intra-urbana, inter-regional e internacional e a tentativa de administrá-las (JESSOP, 2002a). Como vimos, estas novas exigências provocaram a articulação orgânica das cidades empreendedoras com diversas vertentes espacializadas dos SWPR - tornando os sistemas sociais de urbanização regionalizados mais nítidos - e com estratégias espaciais do Estado focalizadoras ou customizadas, perseguidas em múltiplas escalas (BRENNER, 2004).

O voluntarismo das localidades deve ser evitado se pensarmos na constituição de Sistemas Sociais de Produção de Complexos Regionais-Urbanos como sistemas abertos e sob uma perspectiva relacional e anti-essencialista, comenfoque nas interações mas também nas estruturas.Assim, evita-se o risco de que uma imaginação relacional e topológica iniba uma imaginação escalar e territorial(SUNLEY, 2008). Com efeito, a variegação só pode ser corretamente apreendida como uma manifestação relacional de formações econômicas interpenetradas (PECK, 2013). A análise relacional que leva a sério o território não deve se voltar para preocupações sobre como certa interação pode ameaçar a coesão deste território, mas sim entender como alguns interesses territoriais são fortalecidos e como agem na negociação, construção e contestação do tipo de interação estabelecida (JONAS, 2011).Neste sentido, o território não é definido com base em fronteiras dadas, mas socialmente construídas. A área de influência de um SSPCRU não é rigidamente demarcada e será uma região institucionalizada através de vários processos simbólicos, discursivos, e práticas sociais(PAASI, 2002), nos quais uma estratégia hegemônica é definida como "interesse geral” e são diferenciados interna e externamente os vencedores e perdedores.A mobilidade de políticas tem despontado como uma aplicação promissora do pensamento relacional para os estudos urbanos, pois ilustra como a escala urbana só pode ser entendida a partir de suas relações com outras escalas, isto é, através de agentes atuando em várias escalas porém conectados por redes interescalares. Neste sentido, o ponto de partida é entender como as transferências de políticas, ao conectarem cidades diferentes, ajudam a constituí-las. O método para tal é 
criar uma tensão positiva entre territorialidade e relacionalidade (MCCANN e WARD, 2010).

\section{Conclusão}

Este artigo apresentou e discutiu os elementos necessários para uma abordagem críticae institucionalista da produção de complexos regionais e urbanos. Argumentamos que a consideração dos processos de regulação sócio-espacial possibilita um entendimento mais claro das geografias variáveis da regulação e da governança e suas relações com resscalonamentos, des/re-territorialização e surgimento de novos objetos econômicos, políticos e espaciais.

Os processos regulatórios ea variegação reforçam o caráter polimórfico da urbanização, pois ilustram como o espaço não esta simplesmente justaposto, mas sobreposto, intercalado e combinado com múltiplos espaços sociais. Assim, a variegação evidencia novos processos e formas na dialética de diferenciação e interconexão entre os espaços, possibilitando releituras sobre processos de fragmentação territorial.

Por fim, destacamos o papel dos mecanismos de governança, enfatizando a sua maior importância nas vertentes espacializadas do SWPR e conformando o que chamamos de Sistemas Sociais de Produção de Complexos Regionais e Urbanos.

Não obstante as especificidades do fordismo atlântico, o instrumental analítico utilizado neste artigo trata de processos estruturais imanentes ao capitalismo, ainda que as estratégias e políticas adotadas sejam contrangidas diferenciadamente por estas estruturas. Assim, em que pese a necessidade de importantes mediações, acreditamos que sua validade para o contexto periférico é aplicável tanto do ponto de vista teórico como comparativo. Isto abre a oportunidade para uma promissora agenda de pesquisa, que orienta-se para entender: i) o "equivalente funcional" do ajuste espaço-temporal fordista na vigência do Desenvolvimentismo; ii) as contradições internas e externas que culminaram em sua crise; e iii) a substituição tendencial por novo(s) ajuste(s) espaçotemporal(is). Estes elementos podem fornecer subsídios para uma promissora agenda e aplicação empírica dos conceitos aqui discutidos, podendo auxiliar a construção de 
novas tipologias espacializadas que enquadrem novos modelos de governança territorial e escalar presentes em estratégias como as cidades criativas, a governança metropolitana, a mobilidade interjuridiconal de políticas ou o urbanismo neoliberal.O reconhecimento da maior complexidade e emergência de novos atores e escalas territoriais representa maiores desafios para a compreensão dos processos de reescalonamento espacial do Estado após a crise do Estado Desenvolvimentista. Acredita-se que o arcabouço apresentado neste trabalho pode fornecer elementos para o estudo das relações entre política urbana e política escalar, que se tornam mais relevantes num contexto de crise no pacto federativo e maior customização e focalização das políticas espaciais do Estado presentes nos Grandes Projetos Urbanos, nos investimentos seletivos em infraestrutura competitiva e na reforma institucional metropolitana.

\footnotetext{
${ }^{\mathrm{i}}$ Cabe lembrar que esta dicotomia é rejeitada tanto por Benko e Lipietz (2002) como por Gilly e Pecqueur (2002). Entretanto, acreditamos que falta nestes trabalhos uma compreensão de processos de reescalonamento, relativização das escalas e desterritorialização-reterritorialização, o que seria fundamental para se avançar na questão da reprodução do desenvolvimento espacial desigual em múltiplas escalas.
}

\section{Referências}

BATHELT, Harald; GLUCKLER, Johannes.Toward a Relational Economic Geography.Journal of Economic Geography 3, 2003, pp.117-144.

BENKO, Georges; LIPIETZ, Alain.From the régulation of space to the space of régulation. In: BOYER, Robert e SAILLARD, Yves (Eds). Régulation theory: the state of the art. London: Routledge, 2002.

BRENNER, Neil. Regulation theory and the regionalization debate: recent German contributions. Environment and Planning D: Society and Space 1999, volume 17, pp. 645-650.

BRENNER, Neil. New State Spaces: Urban Governance and the Rescaling of Statehood. Oxford: Oxford University Press, 2004, 351p. 
CGEE/IPEAD-UFMG. Governança institucional das cidades. Brasília; Belo Horizonte: CGEE; IPEAD-UFMG, 2010.

COLLINGE, Chris. Self-organisation of society by scale: a spatial reworking of regulation theory. Environment and Planning D: Society and Space 1999, volume 17, pp. $557-574$.

COX, Kevin R; MAIR, Andrew. From localised social structures to localities as agents. Environment and Planning A, 1991, volume 23, pp. 197-213.

CROUCH, Colin; TRIGILIA, Carlo. Conclusions: Still Local Economies in Global Capitalism? In: CROUCH, Colin; LE GALES, Patrick; TRIGILIA, Carlo \& VOELZKOW, Helmut. Local Production Systems in Europe: Rise or Demise? Oxford: Oxford University Press, 2001, 286p.

GILLY, Jean-Pierre; PECQUEUR, Bernard.The local dimension of regulation. In: BOYER, Robert e SAILLARD, Yves (Eds). Régulation theory: the state of the art . London: Routledge, 2002.

HOLLINGSWORTH, J. Rogers; BOYER, Robert.Contemporary Capitalism: The Embeddedness of Institutions (eds). Cambridge: Cambridge University Press, 1997, $493 p$

JESSOP, Bob. Accumulation Strategies, State Forms and Hegemonic Projects. Kapitalistate, 10, pp. 89-112, 1983.

JESSOP, Bob. The regulation approach, governance and post-Fordism: alternative perspectives on economic and political change?,Economy and Society, 24(3), 1995, pp.307-333.

JESSOP, Bob. A Neo-Gramsciam Approach to the Regulation of Urban Regimes: Accumulation Strategies, Hegemonic Projects and Governance. In: LAURIA, Mickey (org). Reconstructing Urban Regime Theory: Regulating Urban Politics in a Global Economy. Thousand Oaks: Sage Publications, 1996. 
JESSOP, Bob. The entrepreneurial city: Re-imaging localities, redesigning economic governance, or restructuring capital? In: JEWSON Nick; MACGREGOR, Susanne (Orgs). Transforming cities: contested governance and new spatial divisions. LONDON: Routledge, 1997, 244p.

JESSOP, Bob. The Future of the Capitalist State. Oxford: Wiley-Blackwell, 2002a, $330 \mathrm{p}$.

JESSOP, Bob. The Crisis of the National Spatio-Temporal Fix and the Tendential Ecological Dominance of Globalizing Capitalism.International Journal of Urban and Regional Research Volume 24(2), 2000 b.

JESSOP, Bob; BRENNER, Neil; JONES, Martin.Theorizing sociospatial relations.Environment and Planning D: Society and Space, volume 26, pp 389-401, 2008.

JONAS, Andrew E.G. Region and place: Regionalism in question. Progress in Human Geography 2011, pp.1-10 .

JONES, Martin. Spatial selectivity of the state?The regulationist enigma and local struggles over economic governance.Environment and Planning A, volume 29, pp. 831-864, 1997

LEYSHON, Andrew. The Transformation of Regulatory Order: Regulating the Global Economy and Environment. Geoforum, Volume 23 No 3, 1992.

LINS, Hoyêdo Nunes. Regulação local: problemática e ensaio de observação. Ensaios FEE, Porto Alegre, v. 27, n. 1, pp. 153-178, maio 2006.

MCCANN, Eugene; WARD, Kevin. Relationality/territoriality: Toward a conceptualization of cities in the world. Geoforum 41, 2010, pp.175-184.

MACLEOD, Gordon. Globalizing Parisian thought-waves: recent advances in the study of social regulation, politics, discourse and space.Progress in Human Geography 21(4), 1997, pp. 530-553. 
MACLEOD, Gordon. Beyond soft institutionalism: accumulation, regulation, and their geographical fixes. Environment and Planning A , 2001, volume 33, pages 1145 1167.

MACLEOD, Gordon; GOODWIN, Mark. Space, scale and state strategy: rethinking urban and regional governance. Progress in Human Geography 23(4), 1999, pp. 503527.

MARTIN, Ron. Institutional Approaches to Economic Geography. In: BARNES, T. and SHEPPARD, Eric. (Orgs).A Companion to Economic Geography, Oxford: Blackwell, 2000. pp.77-94.

MASSEY, Doreen. Politics and Space/Time.New Left Review I/196, 1992

MOURA, Rosa. Conglomerados urbano-regionales: confluência multi-escalar. In: FERNÁNDEZ, V.R.; BRANDÃO, C.A.. (Org.). Escalas y políticas del desarrollo regional. Desafíos para América Latina. 1ed.Buenos Aires: Miño y Dávila, 2010, v. 1, p. $151-184$.

PAASI.ANSSI. Place and region: regional worlds and words. Progress in Human Geography, 26, 2002.

PECK, Jamie. Doing regulation. In: CLARK, GL, FELDMAN, MP; GERTLER, MS (eds). The Oxford Handbook of economic geography. Oxford: Oxford University Press, 2000, pp.61-80.

PECK, Jamie. ForPolanyian economic geographies.Environment and Planning A 45(7) $1545-1568,2013$.

PECK, Jamie; TICKELL, Adam.Local Modes of Social Regulation?Regulation Theory, Thatcherism and Uneven Development.Geoforum, Vol. 23. No 3, 1992, pp. 347-363.

PECK, Jamie; TICKELL, Adam. The social regulation of uneven development: 'regulatory deficit', England's South East, and the collapse of Thatcherism. Environmentand Planning A, volume 27, 1995, pp 15-40. 
POLANYI, Karl. A Grande Transformação: as origens de nossa época. Rio de Janeiro: Elsevier, 2000[1944].

SUNLEY, Peter. Relational Economic Geography: A Partial Understanding or a New Paradigm? EconomicGeography, Vol. 84 No. 1, 2008.

Artigo recebido para publicação em julho de 2014.

Artigo aceito para publicação em novembro de 2014. 